\title{
Improved Processes to Remove Naphthenic Acids
}

\author{
Annual Technical Progress Report
}

(From October 1, 2002 to September 30, 2003)

\author{
Principle Authors
}

Aihua Zhang, Qisheng Ma, William A. Goddard (PI), Yongchun Tang (co-PI),

Date Report was issued: April 28, 2004

DOE Award number: DE-FC26-02NT15383

Name and Address of Submitting Organization

California Institute of Technology

1200 East California Blvd.,

Pasadena, CA91125 


\section{Disclaimer}

This report was prepared as an account of work sponsored by an agency of the United States Government. Neither the United States Government nor any agency thereof, nor any of their employees, makes any warranty, express or implied, or assumes any legal liability or responsibility for the accuracy, completeness, or usefulness of any information, apparatus, product, or process disclosed, or represents that its use would not infringe privately owned rights. Reference herein to any specific commercial products, process, or services by trade name, trademark, manufacturer, or otherwise does not necessarily constitute or imply its endorsement, recommendation, or favoring by the United States Government or any agency thereof. The views and opinions of authors expressed herein do not necessarily state or reflect those of the United States Government or any agency thereof.

\section{Abstract}

In the first year of this project, we have established our experimental and theoretical methodologies for studies of the catalytic decarboxylation process. We have developed both glass and stainless steel micro batch type reactors for the fast screening of various catalysts with reaction substrates of model carboxylic acid compounds and crude oil samples. We also developed novel product analysis methods such as GC analyses for organic acids and gaseous products; and TAN measurements for crude oil. Our research revealed the effectiveness of several solid catalysts such as NA-Cat- 1 and NA-Cat-2 for the catalytic decarboxylation of model compounds; and NA-Cat-5 NA-Cat-9 for the acid removal from crude oil. Our theoretical calculations propose a three-step concerted oxidative decarboxylation mechanism for the NACat-1 catalyst. 


\section{Table of Content}

\section{Improved Processes to Remove Naphthenic Acids}

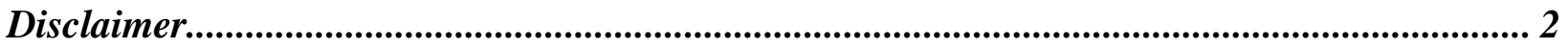

Abstract

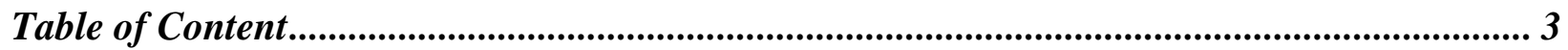

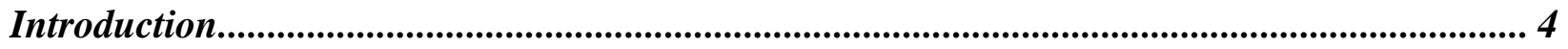

Executive Summary ......................................................................................................................................... 4

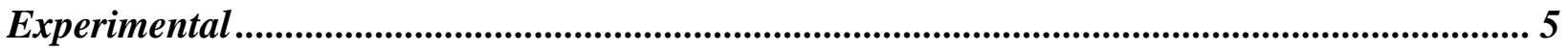

1. Selection of Model Compounds and Oil Samples ......................................................................................5

2. Catalyst Preparations ...................................................................................................................................6

3. Experimental Setups and Operation Procedures ....................................................................................... 7

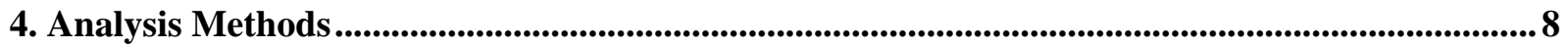

5. Theoretical Calculation Methods ............................................................................................................ 8

Results and Discussion ................................................................................................................. 9

1. Catalytic Decarboxylation of Model Compounds....................................................................................9

2. Catalytic Decarboxylation of the Acid Mixture ............................................................................... 10

3. NA-Cat-1 catalyzed Decarboxylation Reactions ............................................................................. 10

4. Mechanistic Studies of the NA-Cat-1 Catalyzed Decarboxylation Reaction.................................. 12

5. The $\mathrm{CO}_{2}$ Yield vs. the Acid Conversion......................................................................................................13

6. Test Runs with Crude Oil ................................................................................................................................ 13

Conclusion....................................................................................................................................... 15

Work plan for the $2^{\text {nd }}$ and $3^{\text {rd }}$ years (2004 and 2005) ................................................................ 15

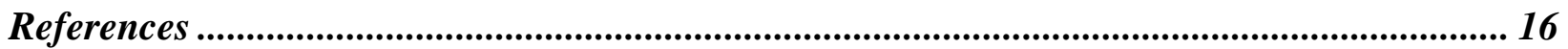




\section{Introduction}

Naphthenic Acid (NA), representing a group of organic acids in crude oils, causes serious corrosion problems in refinery units and transport pipelines. Due to its complex compositional heterogeneity, it is currently difficult to predict the severity of corrosion for an individual or a small group of NA compounds by any analytic measurements. A Total Acidity Number (TAN) or the neutralization number (Neut Number), defined by the number of milligrams of $\mathrm{KOH}$ required to neutralize the acidity in one gram of oil, and is therefore the commonly adopted criterion for predicting the corrosive potential of a crude oil. With this standard, high TAN oils $(>0.5 \mathrm{KOH} / \mathrm{g}$ ) are less desirable than lower TAN oils and are labeled with lower price in market. Crude oils from California, Venezuela, North Sea, Western Africa, India, China and Russia have typically higher naphthenic acid contents.

Developing a naphthenic acid removal process and obtaining a fundamental understanding on the catalytic decarboxylation mechanism will significantly help the petroleum industry of the United State and worldwide in improving refining processing of heavy crude oils possessing high contents of the naphthenic acid. Being sponsored by DOE through this project (DE-FC26-02NT15383), we have assembled a team combining both experimental/theoretical researchers with extended academic/industrial expertise aiming at developing cost-effective methods to remove naphthenic acid from crude oils. Specifically we have two objectives. One objective is to develop a catalytic system to cleanly decarboxylate aliphatic and aromatic acids under low temperature conditions. In particular, we propose to develop a system that will be readily adaptable to removing naphthenic acids from crude oil. Our second objective is to develop an effective solid adsorbent that can remove naphthenic acid via solid liquid separation.

\section{Executive Summary}

Significant progress has been made since this project initiated. Following are the highlights of our achievements:

- Establishing the reaction systems for fast catalyst screenings. Various Batch-Type micro reactors, including sealed glass-tube reactors and stainless steel autoclaves, have been separately designed for the studies of model compounds and crude oils. All of them have been demonstrated to be working efficiently toward our specific requirements.

- Method of product analysis and reaction evaluation was established. For model compounds, primary gaseous products were quantified using GC analysis, while the unreacted acid was recovered using organic solvent through washing the reactor. The latter was subjected to another GC analysis and the acid conversion could be calculated herewith. For crude oil test, TAN measurements were employed to characterize the catalytic effect. 
- Based on the computational studies which indicated that the acidities of naphthenic acids are generally structural insensitive, a set of model compounds has been selected for the purpose of the catalyst screening.

- Catalytic decarboxylation experiments of model compounds, and a mixed acid solution, were carried out using various catalysts, including commercially available chemicals and specifically developed catalysts. Among the early results, NA-Cat-1 exhibited the highest catalytic decarboxylation activity toward model NA compounds, which was recognized from the $\mathrm{CO}_{2}$ formation.

- Detailed theoretical and experimental studies of the decarboxylation reaction catalyzed by NA-Cat-1 have been conducted.

- Another important progress is the observation of the decarboxylation effect of NA-Cat-2 toward model compounds. The $\mathrm{CO}_{2}$ yield well matched the acid conversion; and the decarboxylation product, naphthalene, was also detected. This indicated a direct decarboxylation reaction occurred in the presence of NA-Cat-2.

- Mechanistic understandings of catalytic decarboxylation reactions based on the compounds modeling are continuing. Three major reaction pathways, namely concerted, radical and anionic, are being investigated. A serial of stable, intermediate and transition state configurations are being studied.

- Directly applied the catalyst to the crude oil tests. Improvement of catalytic activity was achieved by doping an active metal on supports. As a result, the TAN could be significantly reduced.

- Two presentations regarding the naphthenic acid removal project were given in the $38^{\text {th }}$ ACS Western Regional Meeting held in Long Beach, CA from October 15 to 18. The titles of our presentations are "Acidity and 1-Octanol/Water Distribution Coefficients of Naphthenic Acids" and "Decarboxylation of Naphthenic Acid Model Compounds". The support of DOE was highly acknowledged.

\section{Experimental}

\section{Selection of Model Compounds and Oil Samples}

a. Model Compounds. A set of carboxylic acids, such as naphthoic acid $\left(\mathrm{C}_{10} \mathrm{H}_{7} \mathrm{COOH}\right)$ and cyclohexane carboxylic acid (CHCA), has been selected as the model compounds to represent the aromatic and saturated naphthenic acids. A majority of catalytic tests with model compounds were performed with naphthoic acid. 
b. Mixed Acid Solution. To apply the catalysts to a reaction system that is close to the actual crude oil in composition, a mixed acid solution was prepared by dissolving five organic acids in dodecane. The structures and concentrations of these acids are listed in Table-1.

Table 1: Composition of the mixed acid solution

\begin{tabular}{|lr|}
\hline Carboxylic acids & Concentrations in dodecane (wt\%) \\
\hline Cyclopentane carboxylic acid (CPCA) & 2.471 \\
Cyclohexane carboxylic acid (CHCA) & 1.927 \\
Benzoic acid (BA) & 0.871 \\
Pentyl-cyclopentane carboxylic acid $\left(\mathrm{C}_{5} \mathrm{H}_{11}-\mathrm{CHCA}\right)$ & 1.099 \\
Heptyl-benzoic acid $\left(\mathrm{C}_{7} \mathrm{H}_{15}-\mathrm{BA}\right)$ & 1.107 \\
\hline
\end{tabular}

c. Oil Sample. With several crude oil samples in hand, we measured their total acid number (TAN), which varied from 0.27 to 4.38 . Among them, Texaco crude oil donated by ChevronTexaco with Total Acid Number (TAN) of 4.38 was selected for our oil test (Figure 1).

\section{Catalyst Preparations}

Commercially available chemicals could be directly used as catalysts or they can be subjected to the activation treatment. For instance NA-Cat- 1 was calcined at $700^{\circ} \mathrm{C}$ for one-hour prior to use. For supported metal catalysts such as $\mathrm{Cu} / \mathrm{SiO}_{2}$, metals were introduced by impregnating their salt solutions to supports followed by evaporation of water and hydrogen reduction at $400{ }^{\circ} \mathrm{C}, 50 \mathrm{ml} / \mathrm{min}$ for $1 \mathrm{hr}$ (Figure 1). For another type of supported metal catalysts, the active metal was doped by thermal decomposition of a metal-containing compound under controlled temperature and vacuum conditions.

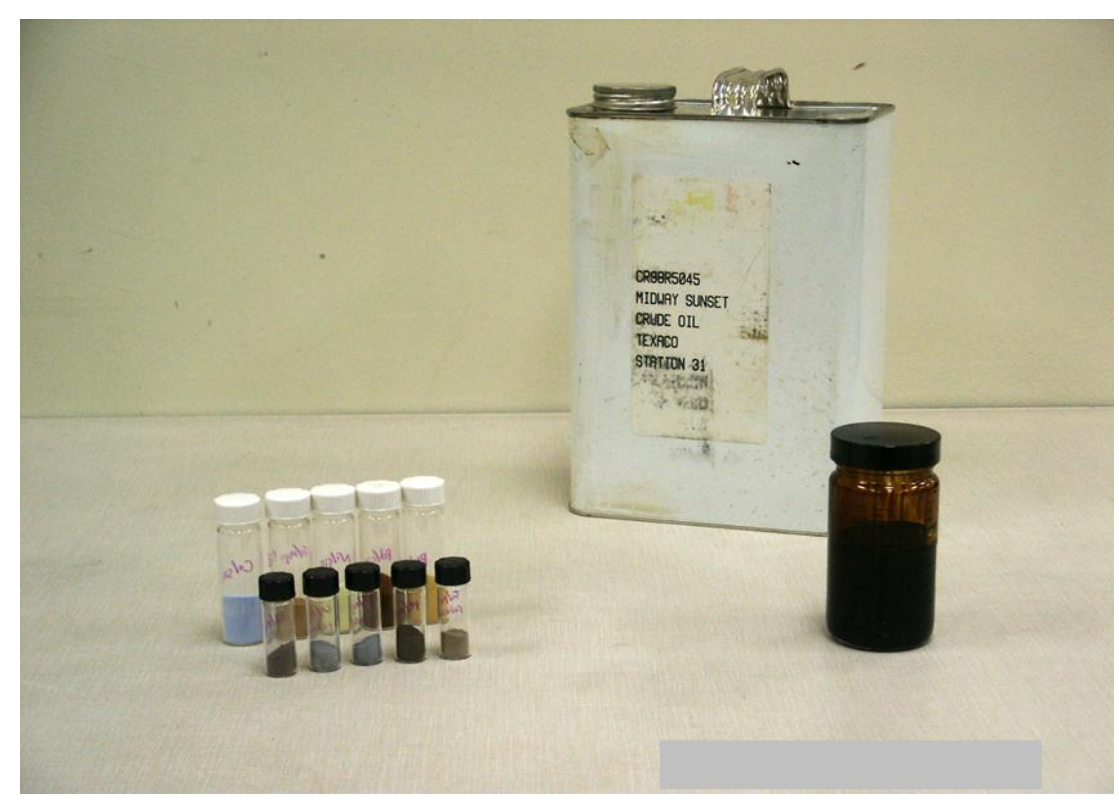

Figure 1: Catalysts and Crude oil Samples 


\section{Experimental Setups and Operation Procedures}

a. Sealed Glass Tube Batch Reactor (Figure 2). Acid sample, catalyst, and other additive (if any), in orders of milligram, were sealed in a glass tube under vacuum. The sealed glass tubes were placed in oven to start reaction under controlled reaction conditions. Typically, the reactions were carried out at the temperature range of 200 to $300{ }^{\circ} \mathrm{C}$ for $4 \mathrm{hrs}$. The reaction gas was collected and quantified in a vacuum line via a standard gas transfer method.

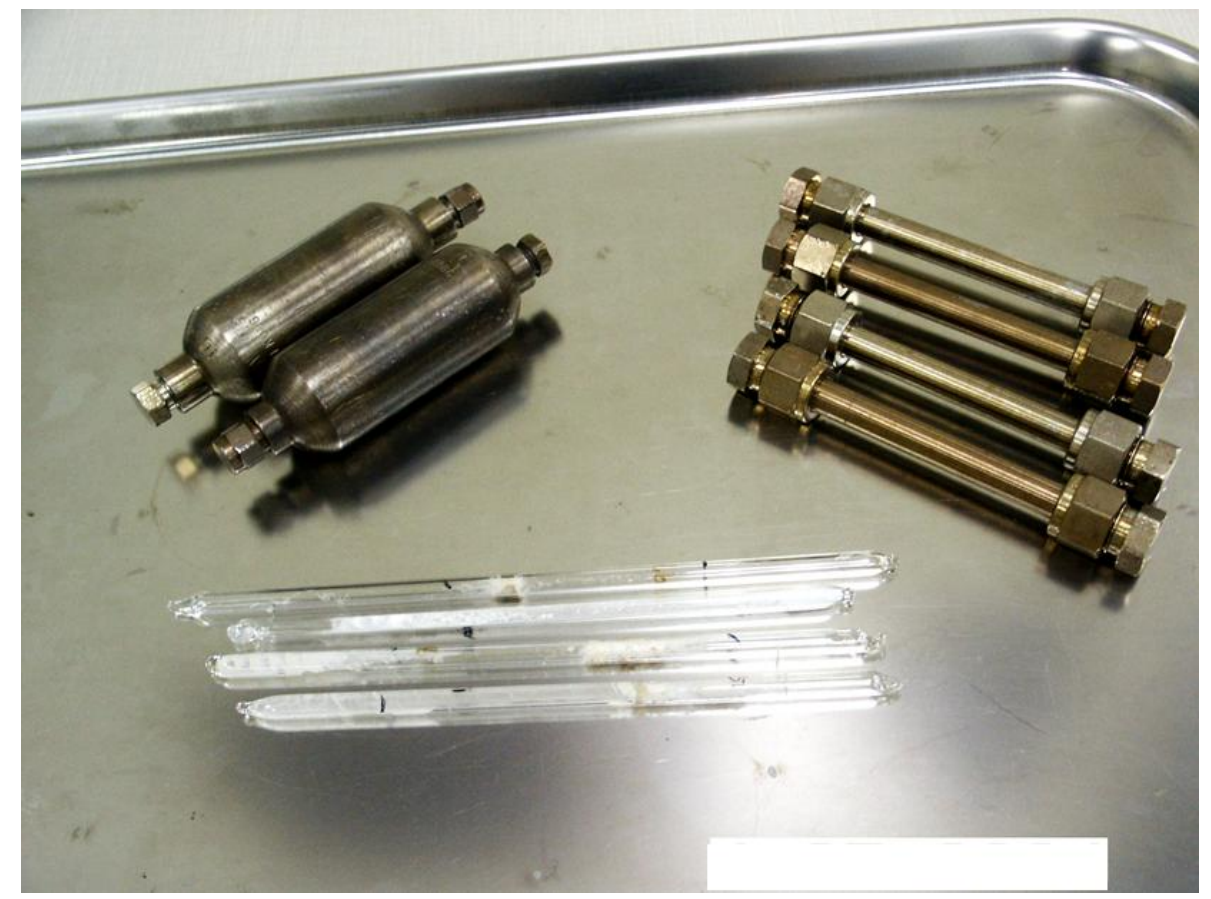

Figure 2: Various Micro Batch Type Reactors

b. Autoclave Reactor (Figure 2). For crude oil test experiments, as more sample amounts are needed for the TAN measurement, a different experimental procedure was established. An autoclave reactor with the volume of ca $40 \mathrm{ml}$ was used to perform the reaction. The detail on the operation procedure can be described as the following: i) loading ca. $12 \mathrm{~g}$ oil and $0.24-0.60 \mathrm{~g}$ catalyst ( $2 \sim 5 \mathrm{wt} \%$ of oil) to the reactor; ii) premixing the two components by shaking the reactor for one hour; iii) running the reaction at the temperature range of $250 \sim 300^{\circ} \mathrm{C}$ for $4 \mathrm{hr}$ while keeping the reactor moving to achieve a good contact between the reactants and catalysts; iv) after undergoing the reaction time, cooling the reactor and then recovering the treated oil through solvent extraction using dichloromethane as the solvent followed by vacuum filtration and evaporation of the solvent. 


\section{Analysis Methods}

a. GC Analyses. The reaction gas was collected and quantified in a vacuum line via a standard gas transfer method (Figure 3). The gas was then analyzed with a GC, which is connected with the vacuum line. $\mathrm{CO}_{2}$ as well as other gaseous products could be quantified herein, from which, the yields of $\mathrm{CO}_{2}$ and other gaseous products could be calculated. For the reaction residue, using dichloromethane to recover the un-reacted acids and then subject to another GC analysis, from which acid conversion could be calculated.

b. Total Acid Number Measurement. For crude oil tests, Total Acid Numbers (TAN), before and after reactions, were measured using a Standard Test Method for Acid Number of Petroleum Products by Potentiometer Titration, ASTM-D 664. Here TAN is defined as the $\mathrm{KOH}$ amount consumed in milligram to neutralize one gram of oil.

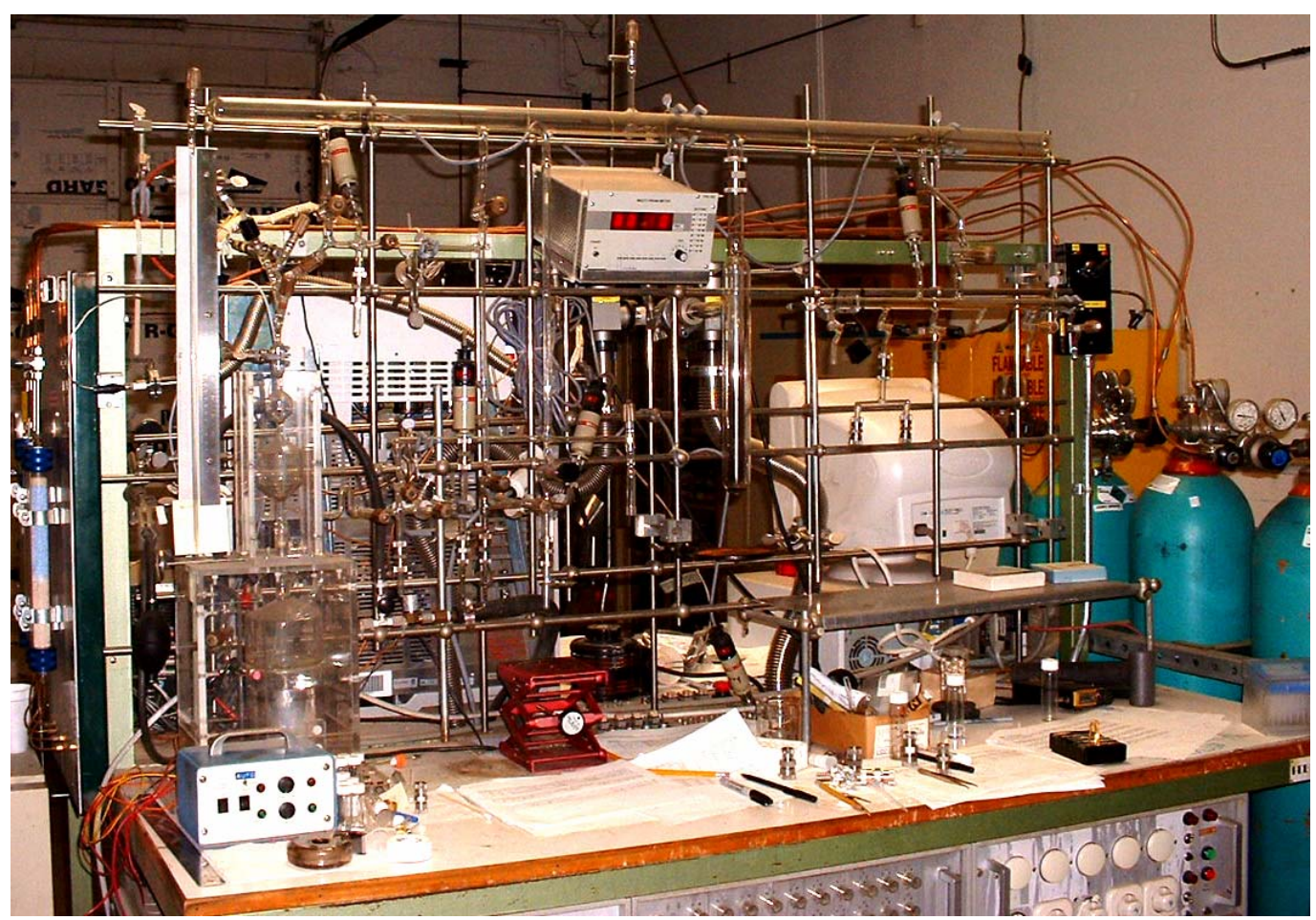

Figure 3: The Gas Transfer and Analysis Apparatus

\section{Theoretical Calculation Methods}

The gas phase geometries of reactants, products, intermediates and transition states (TS) have been optimized using the B3LYP flavor of density functional theory. We have used the 6$31 \mathrm{G}$ (d) basis set for all of computations. All stationary points have positively identified for local minima (zero imaginary frequencies) and for TS (one imaginary frequency). Vibration frequencies are also calculated at all stationary points to obtain zero point energies (ZPE) and thermodynamic parameters. 


\section{Results and Discussion}

\section{Catalytic Decarboxylation of Model Compounds}

Table 2 lists the $\mathrm{CO}_{2}$ generation during the catalytic reactions at $200{ }^{\circ} \mathrm{C}$. Among the solid catalysts investigated, the amounts of the $\mathrm{CO}_{2}$ generated from NA-Cat- 1 catalyzed for both saturated and aromatics (30.38 and $33.20 \mathrm{ml} / \mathrm{g}$, corresponding to the $17.4 \%$ and $25.5 \% \mathrm{~mol}$ conversion) are much higher than other solid catalysts. It should be noticed that no $\mathrm{CO}_{2}$ formation does not necessarily mean no acid conversion, since there is high possibility of $\mathrm{CO}_{2}$ being adsorbed by the metal oxides to form very stable carbonates. However, detection of $\mathrm{CO}_{2}$ does demonstrate the conversion of acid compounds. In this sense, NA-Cat-1 has exhibited the highest reactivity towards the decarboxylation of the naphthenic acid compounds. Addition of the organic bases, such as pyridine, can slightly promote the catalytic reactivity. In the presence of pyridine, NA-Cat- 1 catalyzed decarboxylation can even occur at $100{ }^{\circ} \mathrm{C}$. Several transition metal oxides used here gave poor activities towards the catalytic decarboxylation at this condition.

Table 2: Catalytic Decarboxylation of Model Compounds ${ }^{\mathrm{a}}$

\begin{tabular}{|c|c|c|c|c|c|c|}
\hline \multicolumn{2}{|c|}{ Acid } & \multicolumn{2}{|c|}{ Catalyst } & \multicolumn{2}{|c|}{ Additive (mg) } & \multirow{2}{*}{$\begin{array}{c}\mathrm{CO}_{2} \\
(\mathrm{ml} / \mathrm{g})\end{array}$} \\
\hline Name & wt. (mg) & Name & Wt. (mg) & Name & wt. (mg) & \\
\hline CHCA & 49.3 & NA-Cat-1 & 10.2 & & & 30.38 \\
\hline CHCA & 50.9 & NA-Cat-5 & 14.3 & & & 0.00 \\
\hline CHCA & 51.9 & $\mathrm{BaO}$ & 11.5 & & & 0.02 \\
\hline CHCA & 46.1 & $\mathrm{SrO}$ & 11.5 & & & 0.00 \\
\hline NA & 51.5 & None & & & & 0.00 \\
\hline NA & 52.8 & NA-Cat-1 & 19.7 & & & 33.20 \\
\hline NA & 50.8 & $\mathrm{CuO}$ & 11.3 & & & 0.00 \\
\hline NA & 52.4 & $\mathrm{Cu}_{2} \mathrm{O}$ & 11.7 & & & 0.00 \\
\hline NA & 53.1 & $\mathrm{Ag}_{2} \mathrm{O}$ & 10 & & & 0.00 \\
\hline NA & 50.5 & $\mathrm{Al}_{2} \mathrm{O}_{3}$ & 10.1 & & & 0.00 \\
\hline NA & 50.1 & $\mathrm{Ag}_{2} \mathrm{O}$ & 9.9 & $\mathrm{C}_{5} \mathrm{H}_{5} \mathrm{NO}$ & 52.8 & 4.40 \\
\hline NA & 49.1 & $\mathrm{Cu}_{2} \mathrm{O}$ & 9.6 & $\mathrm{C}_{5} \mathrm{H}_{5} \mathrm{NO}$ & 48.4 & 5.60 \\
\hline NA & 52.7 & NA-Cat- ${ }^{b}$ & 21.3 & Pyridine & 56.2 & 20.80 \\
\hline NA & 49.5 & $\mathrm{Ni} / \mathrm{Al}_{2} \mathrm{O}_{3}$ & 10.9 & & & 0.10 \\
\hline NA & 49.2 & $\mathrm{Ni} / \mathrm{SiO}_{2}$ & 11.6 & & & 0.00 \\
\hline
\end{tabular}

${ }^{\text {a }}$ Reaction temperature and time are $200{ }^{\circ} \mathrm{C}$ and $4 \mathrm{hrs}$, except for ${ }^{\mathrm{b}}$ reaction temperature and time for $100{ }^{\circ} \mathrm{C}$ and $4 \mathrm{hrs}$. 


\section{Catalytic Decarboxylation of the Acid Mixture}

To test the effectiveness of the NA-Cat-1 series catalyst on decarboxylation of organic acids, a mixture of five acid compounds is prepared to partly simulate oil composition, but with higher concentrations of acids. As listed in Table 3, compared with no catalyst addition, high acid conversions were obtained from NA-Cat-1 for each acidic compound, which is similar with the case of single acid test. The acid conversions were further improved when small amounts of active metals were loaded on NA-Cat-1 (NA-Cat-3, NA-Cat-4), and the conversions even exceeded $90 \%$.

Table 3: Catalytic Decarboxylation of Acid Mixture ${ }^{a}$

\begin{tabular}{c|c|c|c|c|c|c|c}
\hline $\begin{array}{c}\text { Mixture } \\
\text { wt. (g) }\end{array}$ & \multicolumn{2}{|c|}{ Catalyst } & \multicolumn{5}{c}{ Acid Conversions } \\
\hline 2.4870 & Name & wt. (mg) & CPCA & CHCA & BA & $\begin{array}{c}\text { C5H11- } \\
\text { CHCA }\end{array}$ & $\begin{array}{c}\text { C7H15- } \\
\text { BA }\end{array}$ \\
\hline 2.5261 & & 16.00 & 15.00 & 14.50 & 11.30 & 7.00 \\
2.5357 & $\mathrm{Ni}^{\prime} \mathrm{Al}_{2} \mathrm{O}_{3}$ & 25.80 & 5.00 & 5.70 & 15.00 & 10.70 & 4.80 \\
2.5511 & $\mathrm{NA} / \mathrm{SiO}_{2}$ & 25.50 & 21.50 & 18.90 & 15.40 & 16.00 & 8.70 \\
2.3755 & $\mathrm{Cu} / \mathrm{Al}_{2} \mathrm{O}_{3}$ & 25.50 & 70.80 & 70.50 & 91.20 & 92.40 & 97.50 \\
2.3806 & $\mathrm{Cu} / \mathrm{SiO}_{2}$ & 25.00 & 0.00 & 0.00 & 5.50 & 2.40 & 5.30 \\
2.4960 & $\mathrm{NA}-\mathrm{Cat}-4$ & 25.40 & 86.50 & 10.50 & 10.40 & 7.10 & 3.50 \\
2.5432 & $\mathrm{NA}-\mathrm{Cat}-1$ & 25.50 & 39.00 & 46.70 & 92.40 & 93.20 & 98.00 \\
\hline
\end{tabular}

${ }^{a}$ CPCA, cyclopentane carboxylic acid; CHCA, cyclohexane carboxylic acid, BA, benzoic acid.

\section{NA-Cat-1 Catalyzed Decarboxylation Reactions}

The effects of temperature and catalyst loading on naphthenic acid decomposition were investigated with NA-Cat-1. The reactions were separately run by changing reaction temperature in the range of 100 to $300{ }^{\circ} \mathrm{C}$ at a fixed NA-Cat-1 loading, $20 \mathrm{wt} \%$, and changing the NA-Cat-1 loading from 0 to $40 \mathrm{wt} \%$ at $250{ }^{\circ} \mathrm{C}$. Gaseous and remaining solid products were analyzed to obtain the data for $\mathrm{CO}_{2}$ yield and acid conversion.

From the results shown in Figure 4, it can be seen that the reaction initialized at around $150{ }^{\circ} \mathrm{C}$, followed by a sharp increase in range of $150-250{ }^{\circ} \mathrm{C}$ and then tended to level off at higher temperature. After $250{ }^{\circ} \mathrm{C}$, more than $80 \%$ of acid has been converted, while the $\mathrm{CO}_{2}$ yield was not as high. Increasing of the NA-Cat-1 loading in the range of $0-20 \mathrm{wt} \%$ linearly increases the $\mathrm{CO}_{2}$ yield and the acid conversion, but further increasing of the NA-Cat-1 loading gave only limited enhancement.

On the role of NA-Cat-1, we currently consider its dual functionalities, namely catalytic decarboxylation and neutralization. Due to these two important features, it can be enrolled as a hopeful candidate to realize our two objectives. 

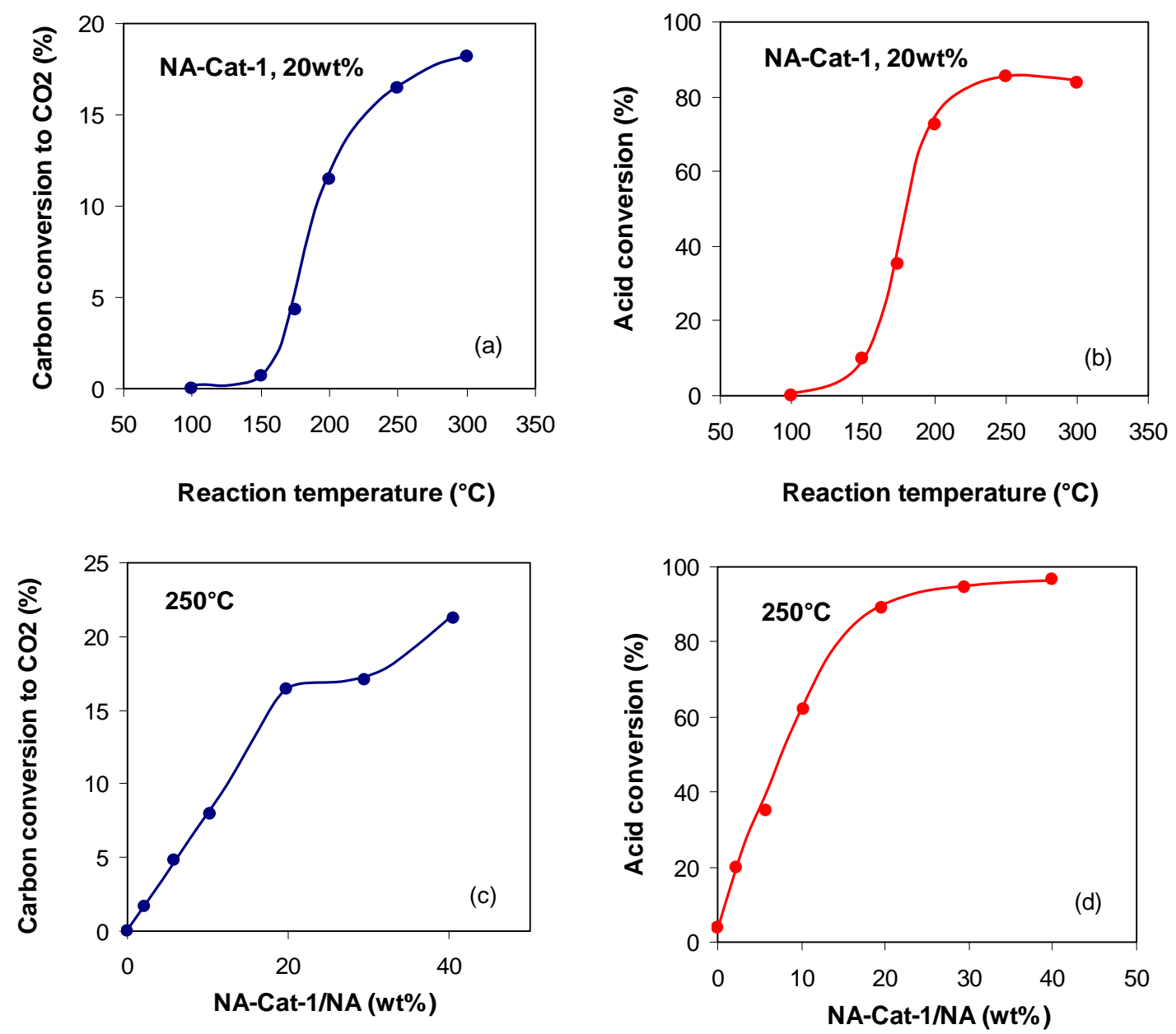

Figure 4: NA-Cat-1 Catalyzed Decarboxylation Reactions (a, b) temperature effects; and (c, d) catalyst-loading effects

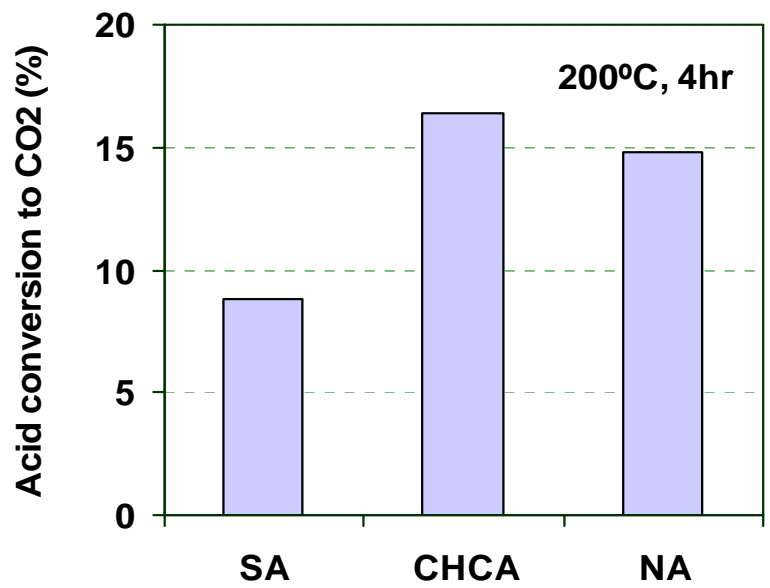

Figure 5: NA-Cat-1 Catalyzed Decarboxylation Reactions on Different Carboxylic Acids SA, Succinic acid; CHCA, Cyclohexane carboxylic acid; NA, naphthoic acid 
To test the applicability of NA-Cat-1, we applied it to the model compound reaction with diverse reaction substrates (Figure 5). The three reaction substrates represent different acid structures, which are aliphatic, alicyclic and aromatic respectively. In each reaction, $\mathrm{CO}_{2}$ formation was detected. This result indicates that NA-Cat-1 is able to promote catalytic decarboxylation for the acid substrates with different structures; in another word, this reaction is less acid-structure dependent.

\section{Mechanistic Studies of the NA-Cat-1 Catalyzed Decarboxylation Reaction}

A plausible concerted oxidative decarboxylation pathway in the presence of NA-Cat-1 has been theoretically studied in gas-phase with the energy diagram of all of stable, intermediate and transition states computed. The reaction path can be summarized as a three-step mechanism that converts benzoic acid to phenol (Figure 6):

Step 1: Nucleophilic attack at the $C$ atom of the carboxyl group, from (A) to (B)

Step 2: Transfer of the hydroxy group via a 4-member ring transition state, from (B) to (D) through TS-1 (C)

Step 3: Proton transfer accomplishing by decarboxylation, from (D) to (F) through TS-2 (E).

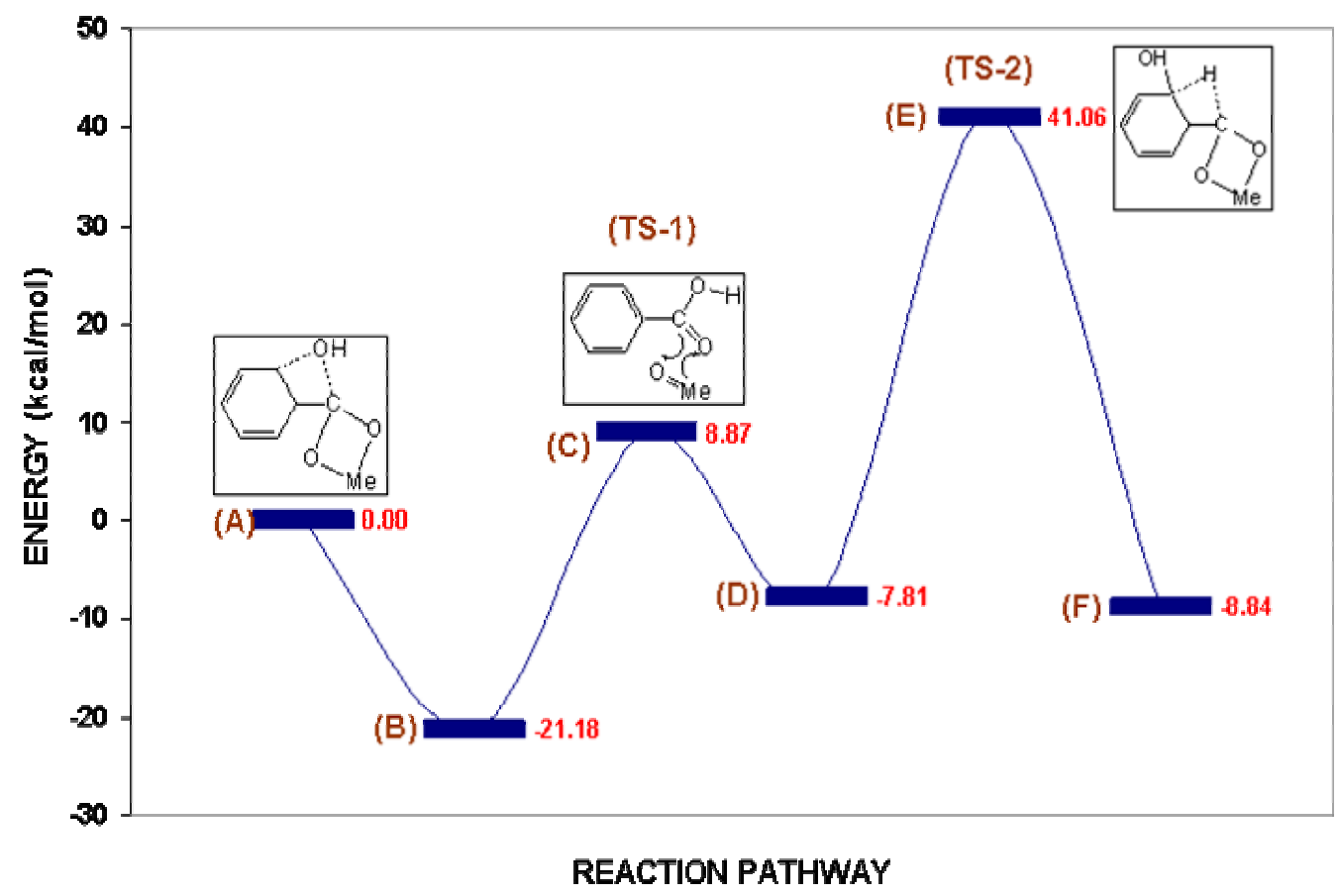

Figure 6: A Plausible Concerted NA-Cat-1 Catalyzed Decarboxylation Pathway

The computed transition barrier for TS-1, featuring the attack of the hydroxy group on the ortho-position of the aromatic ring $(\sim 30 \mathrm{kcal} / \mathrm{mol})$ is consistent with our experimental conditions $\left(200{ }^{\circ} \mathrm{C}, 4 \mathrm{hrs}\right)$. The barrier for TS-2, featuring proton transferring from ortho- to ipso- (49 kcal/mol), however, is higher than expected. This could be partially due to the fact that 
only gas-phase single molecule calculations were performed. Further calculations with larger metal oxide clusters, and/or water assisting are expected to lower this barrier.

\section{The $\mathrm{CO}_{2}$ Yield vs. the Acid Conversion}

Even though many of the metal oxides tested did not show activities towards the $\mathrm{CO}_{2}$ generation, it does not necessarily mean that no acids have been removed. In fact, by comparing the $\mathrm{CO}_{2}$ yield and the acid conversion in the presence of several metal oxides, as shown in Table 4 , it can be seen that the acid conversions are generally higher than the $\mathrm{CO}_{2}$ yields. This large difference could be due to either the formation of carboxylic acid salts through acid-base neutralization reaction, or the formation of alkaline earth metal carbonates through the adsorption of $\mathrm{CO}_{2}$ on oxides. The latter should also be a signature of catalytic decarboxylation process. In a sense, the case of NA-Cat-2 is an ideal decarboxylation catalyst as the acid conversion is almost equal with its $\mathrm{CO}_{2}$ yield and the decarboxylated product, naphthalene, was also clearly detected, whose carbon yield reached ca.20\%. This result clearly identified the occurrence of a catalytic decarboxylation process.

Table 4: The $\mathrm{CO}_{2}$ Yield and the Acid Conversion in the Presence of Several Metal Oxides

\begin{tabular}{c|c|c}
\hline Catalyst & Acid Conversion (\%) & CO2 Yield (\%) \\
\hline None & 3.6 & 0.05 \\
NA-Cat-1 & 81.6 & 17.1 \\
NA-Cat-5 & 96.9 & 0 \\
SrO & 69.9 & 0 \\
BaO & 53.8 & 0.15 \\
NA-Cat-2 & 53.7 & 53.1 \\
CuO & 63.3 & 17.2 \\
\hline
\end{tabular}

Reaction temperature: $250^{\circ} \mathrm{C}$; reaction time: $4 \mathrm{hr}$

\section{Test Runs with Crude Oil}

The results of initial test runs of a group of metal oxide catalysts as reagents towards the decarboxylation reaction of crude oils are listed illustrated in Figure 7. Here the acid conversions were calculated based on the TAN reduction. NA-Cat-5 shows acid conversion as high as $\sim 70 \%$, while NA-Cat-1 did not show significant reactivity towards the acid removal as expected, and NA-Cat-2 and $\mathrm{CuO}$ almost had no positive influence to this process. It seems that there are many others

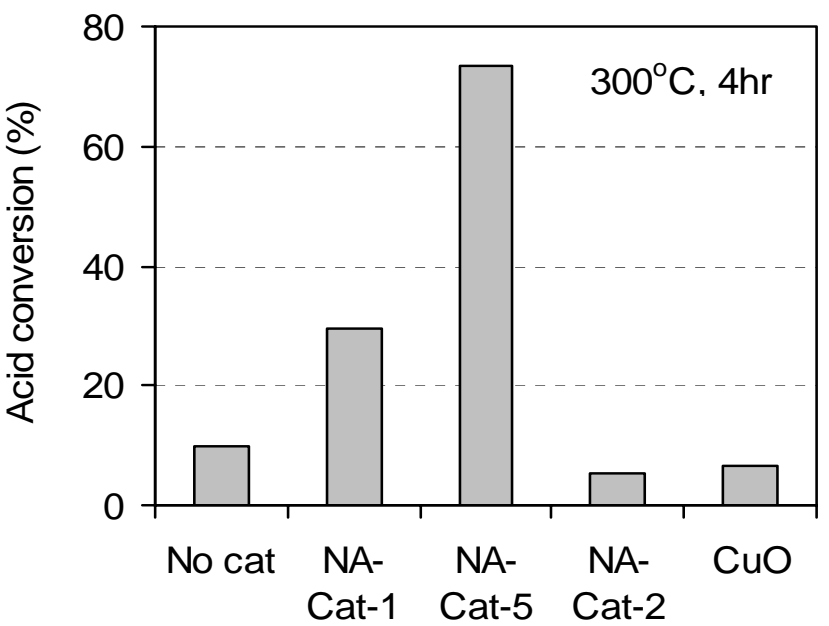

Figure 7: Acid Conversion of the Texaco Oil Sample on Various Metal Oxide Catalysts 
factors that affect the performance of the catalysts in crude oil reaction. In particular, catalytic deactivation that resulted from the impurities in crude oils is an important issue.

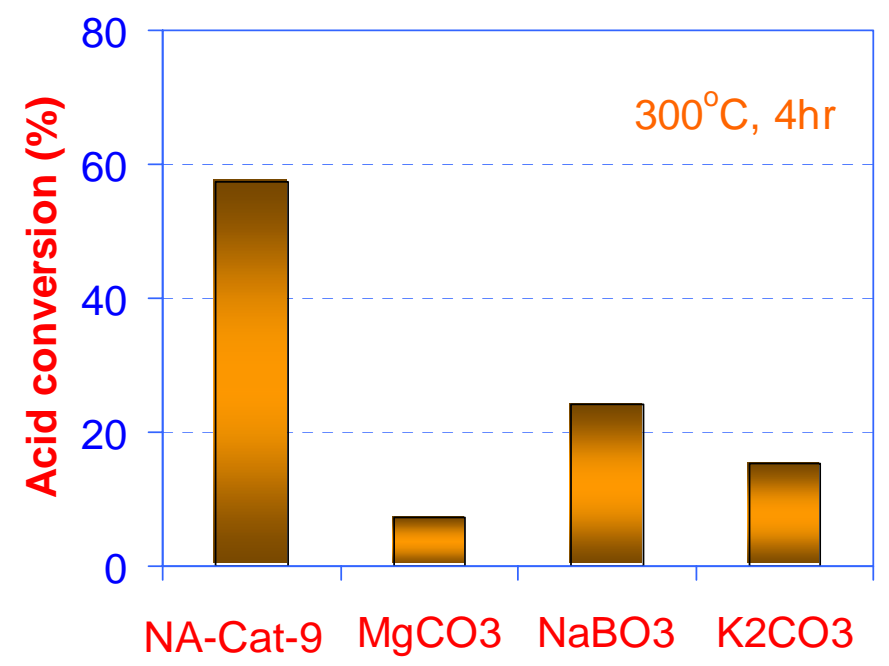

Figure 8: Acid Conversion of the Texaco Oil Sample on Various Carbonate Catalysts

To improve the behavior of catalyst and promote the acid removal of crude oil, more autoclave tests were performed with a group of carbonates used as catalysts (Figure 8) and several active metal supported catalysts (Figure 9), which were specifically developed for this purpose. Among the carbonates tested, NA-Cat-9 gave relatively high acid conversion compared with others; NA-Cat-6, NA-Cat-7 and NA-Cat-8 were identified to be very effective in reducing the acidity of crude oil. These findings gave us new insight on the process that we are currently working with.

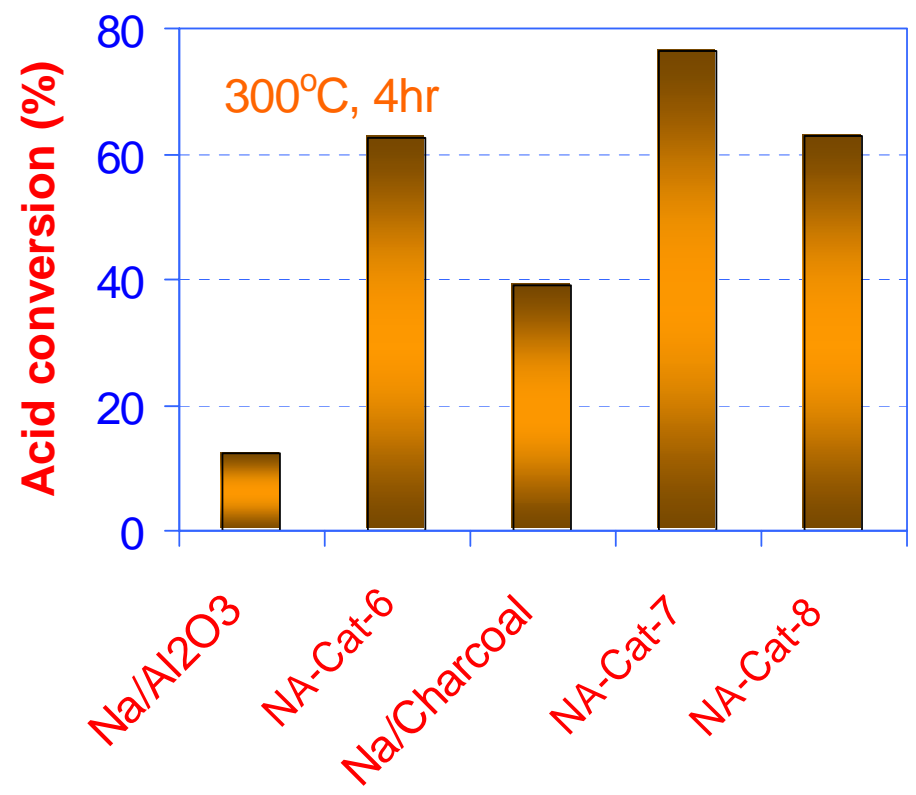

Figure 9: Acid Conversion of the Texaco Oil Sample on Various Active Meta-Supported Catalysts 


\section{Conclusion}

In the first year of this project, we have established our experimental and theoretical methodology for the study of catalytic decarboxylation and acid removal from crude oil and obtained promising results.

- Our research revealed the effectiveness of several solid catalysts such as NA-Cat-1 and NA-Cat-2 for the catalytic decarboxylation of model compounds and mixed acid solution.

- Several improved catalysts were found to be very effective in acid removal from crude oil, and significant TAN reduction was observed.

- We have obtained preliminary understanding on the reaction mechanism and other aspects related to the projects.

\section{Work plan for the $2^{\text {nd }}$ and $3^{\text {rd }}$ years (2004 and 2005)}

Our efforts for the $2^{\text {nd }}$ and $3^{\text {rd }}$ years of this project will follow the outline as proposed in our proposal to i) develop an advanced catalytic system that can effectively remove naphthenic acid from model compounds and crude oils; ii) improve the fundamental understanding of the decarboxylation reaction mechanism; and iii) develop a readily adaptable naphthenic acid removal via solid liquid separation.

To achieve these goals, several action plans will be taken:

- More experimental tests of our developed catalytic systems in the crude oils,

- Design and synthesis of new solid catalysts that can significant lower the acidity of crude oil and keep long catalytic life,

- More dynamic measurements with the developed catalysts for crude oil using time resolved multiple cold trap

- Detailed surface characterization of pure solid catalysts using XRD and XPS analysis.

- A detailed mechanistic understanding of decarboxylation reaction combining the theoretical and experimental efforts,

- Computational modeling of the adsorption of naphthenic acid on the solid surfaces,

- Establishing of experimental procedure to develop solid adsorbent approach,

- Develop and optimize a process for efficiently removing naphthenic acids from crude oil based on the experimental and the computational results. 


\section{References}

1. W. A. Derungs, Corrosion 1956, 12(2) 41.

2. R. L. Piehl, Corrosion 1960, 16, 6.

3. J. J. Heller; R. D. Merick and E. B. Marquand, NACE Publication 8B163, Materials Protection 1963, 2(9), 44.

4. J. Guteit, Materials Performance 1977, 33(10) 24.

5. N. A. Tomczyk and R. E. Winans, Energy \& Fuels, 2001, 15, 1498-1504.

6. Naoto Chatani, Hiroto Tatamidani, Yutaka Ie et al. J. Am Chem Soc, 2001, 123, 48494850.

7. Marek Glinski and Jacek Kijenski, React. Kinet. Cataly. Lett 69 (1) 123-128 (2000).

8. Leon M. Stock and Marcus Obeng, Energy \& Fuels 1997, 11, 987-997.

9. F. P. W. Agterberg, W.L. Driessen et al, New Developments in Selective Oxidation II (Elsevier Science) 639-646 (1994).

10. US Patent $5,871,637$

11. US Patent 6,096,196

12. US Patent $6,961,821$ 